\title{
MODELLING UNCERTAINTIES IN MULTI-CRITERIA DECISION MAKING USING DISTANCE MEASURE AND TOPSIS FOR HESITANT FUZZY SETS
}

\author{
Ismat Beg ${ }^{1}$, Tabasam Rashid ${ }^{2}$ \\ ${ }^{1}$ Lahore School of Economics, Lahore, Pakistan \\ ${ }^{2}$ University of Management and Technology, Lahore-54770, Pakistan
}

\begin{abstract}
A notion for distance between hesitant fuzzy data is given. Using this new distance notion, we propose the technique for order preference by similarity to ideal solution for hesitant fuzzy sets and a new approach in modelling uncertainties. An illustrative example is constructed to show the feasibility and practicality of the new method.
\end{abstract}

Keywords: uncertainty modelling, multiple criteria analysis, group decisions and negotiations, hesitant fuzzy set, TOPSIS

2010 Mathematics Subject Classification: 91B06; 91B10; 03B52; 03E72; $68 T 37$.

\section{Introduction}

Real world decision making problems are quite challenging because of the difficulty of modeling and coping with uncertain situation. One of the most commonly used approaches in multiple criteria decision making problems is the technique for order preference by similarity to ideal solution (TOPSIS). Hwang and Yoon [11] developed TOPSIS for multiple criteria based decision making (MCDM) problems. TOPSIS is an effective technique for the selection of suitable alternative and to rank the alternatives from best to worst or vice versa $[1,2,5,13,14]$. The MCDM provides a framework for comparison of different alternatives based on different criteria. Ranking of alternatives in the TOPSIS work on the concept of distances between alternatives and ideal solutions. Kim et al. [15] and Shih et al. [22] addressed four advantages of TOPSIS:

- It has sound logic to represent the rationale of human choice;
- It has scalar value to consider the best and worst alternative simultaneously;

- It has a simple computation process and can be easily programmed;

- It has ability of the performance measures of all alternatives on attributes to be visualized on a polyhedron, at least for any two dimensions.

Representation of human preference is not suitably possible with exact numeric values for real world decision problems. To handle uncertainty, fuzzy set theory and its different generalizations have been developed and used. Bellman and Zadeh [4] proposed the concept of fuzzy set theory in decision making for the solution of ambiguity in information from human preference. Dubois [9] gave a comparison about some old and new techniques for fuzzy decision analysis. Fuzzy numbers are applied to establish a fuzzy TOPSIS $[7,18]$ and fuzzy TOPSIS has been further developed by several authors $[3,6,8,12,16,17,20,24,25,26]$. Hesitant fuzzy sets that have been recently introduced in 
[23] provide a very interesting extension of fuzzy sets. They try to manage those situations, where a set of values are possible in the definition process of the membership of an element. In [19, 21, 27] hesitant fuzzy sets are used to obtain multiple attribute decision making. The aim of this paper is to two fold; the first one is to extend fuzzy TOPSIS for hesitant fuzzy sets under the opinion of decision makers, and the second one is the new approach in modelling uncertainties. In the proposed method TOPSIS and HFS is, for the first time used simultaneously.

This article is organized as follows: In Section 2, some preliminary concepts are given to understand our proposal. In Section 3, we gave a notion of distance between HFE's and fuzzy TOPSIS is constructed for HFS. Then in Section 4, the proposed fuzzy TOPSIS method is applied to see its feasibility. Conclusion of the paper is given in the last Section.

\section{Preliminaries}

A fuzzy set $B$ in the universe $X$ is a mapping from $X$ to $[0,1]$. The value $B(x)$ is called the degree of membership of $x$ in $B$. Torra [23] introduced hesitant fuzzy sets (HFS) as a generalization of fuzzy sets.

Definition 1 [23] A hesitant fuzzy set on $X$ is a function $h$ that when applied to $X$ returns a subset of $[0,1]$, which can be represented as the following mathematical symbol:

$$
E=\{(x, h(x)) \mid x \in X\},
$$

where $h(x)$ is a set of some values in $[0,1]$, denoting the possible membership degrees of the element $x \in X$ to the set $E$. For convenience, Xia and Xu [28] named $h(x)$ a hesitant fuzzy element (HFE).

A typical hesitant fuzzy set is a fuzzy set where $h(x)$ is a finite subset of $[0,1]$. Examples of hesitant fuzzy sets are given below where $h(x)$ represents the possible membership values of the set at $x$.

It is noted that the number of values in different HFEs may be different, let $l_{h(x)}$ be the number of values in $h(x)$. In case values in an HFE are out of order; we can arrange them in such a order, that an HFE $h$, let $\sigma:(1,2, \ldots, n) \rightarrow(1,2, \ldots, n)$ be a permu- tation satisfying $h_{\sigma(i)} \leq h_{\sigma(i+1)}, i=1,2, \ldots, l_{h}-1$. $\mathrm{Xu}$ and Xia [29] proposed that two HFEs $h_{1}$ and $h_{2}$ have the same length $l$ and $h_{1_{\sigma(i)}}=h_{2_{\sigma(i)}}$ if and only if $h_{1}=h_{2}$, for $i=1,2, \ldots, l$.

Example 1 [23] Let Xbe a reference set, then following are some hesitant fuzzy sets;

Empty Set: $h(x)=\{0\}$ for all $x$ in $X$.

Full Set: $h(x)=\{1\}$ for all $x$ in $X$.

Complete ignorance for a $x \in X$ (all is possible): $h(x)=[0,1]$.

Nonsense for a $x \in X: h(x)=\emptyset$.

Definition 2 [23] Let $X$ be a reference set and $h$ be a HFS. The upper bound $h^{+}(x)$ and lower bound $h^{-}(x)$ for a $x \in X$ are defined as
1) Upper bound: $h^{+}(x)=\operatorname{maxh}(x)$.
2) Lower bound: $h^{-}(x)=\operatorname{minh}(x)$.

Example 2 Consider a hesitant fuzzy set A given by

$A=\left\{\left(x_{1},(0.2,0.3,0.6,0.9)\right),\left(x_{2},(0.1,0.4,0.5,0.7)\right)\right\}$

Then

$h_{A}^{+}\left(x_{1}\right)=\max (0.2,0.3,0.6,0.9)=0.9, \quad$ and $h_{A}^{+}\left(x_{2}\right)=\max (0.1,0.4,0.5,0.7)=0.7$, and $h_{A}^{-}\left(x_{1}\right)=\min (0.2,0.3,0.6,0.9)=0.2$, and $h_{A}^{-}\left(x_{2}\right)=\min (0.1,0.4,0.5,0.7,1)=0.1$.

Definition 3 [23] For a hesitant fuzzy set represented by its membership function $h$, we define its complement as follows:

$$
h^{c}(x)=\underset{\gamma \in h(x)}{\cup}\{1-\gamma\} .
$$

Example 3 Consider a hesitant fuzzy set A such that

$A=\left\{\left(x_{1},(0.2,0.3,0.6,0.9)\right),\left(x_{2},(0.1,0.4,0.5,0.7,1)\right)\right\}$

Then complement of $A$ is given by

$A^{c}=\left\{\left(x_{1},(1-0.2,1-0.3,1-0.6,1-0.9)\right)\right.$,

$\left.\left(x_{2},(1-0.1,1-0.4,1-0.5,1-0.7,1-1)\right)\right\}$

$=\left\{\left(x_{1},(0.8,0.7,0.4,0.1)\right),\left(x_{2},(0.9,0.6,0.5,0.3,0)\right)\right\}$.

Definition 4 [23] Given two hesitant fuzzy sets represented by their membership functions $h_{1}$ and $h_{2}$, 
- their union represented by $h_{1} \cup h_{2}$ as

$$
\begin{gathered}
\left(h_{1} \cup h_{2}\right)(x)= \\
\left\{h \in\left(h_{1}(x) \cup h_{2}(x)\right) \mid h \geq \max \left(h_{1}^{-}(x), h_{2}^{-}(x)\right)\right\} . \\
- \text { their intersection represented by } h_{1} \cap h_{2} \text { as } \\
\left(h_{1} \cap h_{2}\right)(x)= \\
\left\{h \in\left(h_{1}(x) \cap h_{2}(x)\right) \mid h \leq \min \left(h_{1}^{+}(x), h_{2}^{+}(x)\right)\right\} .
\end{gathered}
$$

Example 4 Consider two hesitant fuzzy sets $A$ and $B$ such that

$A=\left\{\left(x_{1},(0.2,0.4,0.6)\right),\left(x_{2},(0.5,0.7,1)\right)\right\}$,

and

$B=\left\{\left(x_{1},(0,0.4,0.8)\right),\left(x_{2},(0.2,0.3,0.45,0.9)\right)\right\}$.

Then

$$
A \cup B=
$$$$
\left\{\left(x_{1},(0.2,0.4,0.6,0.8)\right),\left(x_{2},(0.5,0.7,0.9,1)\right)\right\}
$$

and

$$
A \cap B=
$$

$\left\{\left(x_{1},(0,0.2,0.4,0.6)\right)\right.$,

$\left.\left(x_{2},(0.2,0.3,0.45,0.5,0.7,0.9)\right)\right\}$.

$\mathrm{Xu}$ and Xia [29] gave six different distance formulae for HFE's. But in their distance formulae two HFE's should have the same length, so their distance formulae are not applicable for any two HFE's with different length. Motivated by the Hausdorff distance, we give a distance notion for any two HFE's.

Definition 5 Let $x$ and $y$ be the two HFEs, such that $x=\left\{a_{1}, a_{2}, \ldots, a_{n}\right\}$ and $y=\left\{b_{1}, b_{2}, \ldots, b_{m}\right\}$, then distance ' $d$ ' between $x$ and $y$ is defined as

$$
d(x, y)=
$$

$\max \left\{\max _{a_{j} \in x}\left\{\min _{b_{i} \in y}\left(\left|a_{j}-b_{i}\right|\right)\right\}, \max _{b_{i} \in y}\left\{\min _{a_{j} \in x}\left(\left|a_{j}-b_{i}\right|\right)\right\}\right\}$.

It is easy to show that this distance ' $d$ ' satisfies the following properties.

1. $d(x, y)=0$ if and only if $x=y$;

2. $d(x, y)=d(y, x)$.
Example 5 As in above example $A\left(x_{1}\right)=$ $\{0.2,0.4,0.6\}$ and $B\left(x_{1}\right)=\{0,0.2,0.4,0.6\}$, Now we want to calculate distance between them.

$d\left(A\left(x_{1}\right), B\left(x_{1}\right)\right)=\max \{\max \{\min (|0.2-0|, \mid 0.2-$ $0.2|| 0.2-,0.4|| 0.2-0.6 \mid,), \min (|0.4-0|, \mid 0.4-$ $0.2|| 0.4-,0.4|| 0.4-0.6 \mid,), \min (|0.6-0|, \mid 0.6-$ $0.2|| 0.6-,0.4|| 0.6-0.6 \mid),\}, \max \{\min (|0-0.2|$, $|0-0.4|,|0-0.6|), \min (|0.2-0.2|,|0.2-0.4|$, $|0.2-0.6|), \min (|0.4-0.2|,|0.4-0.4|, \mid 0.4-$ $0.6 \mid), \min (|0.6-0.2|,|0.6-0.4|,|0.6-0.6|)\}\}$

$d\left(A\left(x_{1}\right), B\left(x_{1}\right)\right)=\max \{\max \{\min (0.2,0,0.2,0.4)$, $\min (0.4,0.2,0,0.2), \min (0.6,0.4,0.2,0)\}$, $\max \{\min (0.2,0.4,0.6), \min (0,0.2,0.4), \min (0.2$, $0,0.2), \min (0.4,0.2,0)\}\}$

$d\left(A\left(x_{1}\right), B\left(x_{1}\right)\right)=\max \{\max \{0,0,0\}, \max \{0.2,0$, $0,0\}\}$

$d\left(A\left(x_{1}\right), B\left(x_{1}\right)\right)=\max \{0,0.2\}=0.2$.

\section{TOPSIS for HFS}

We give construction of TOPSIS using the proposed notion of distance, which is then used for multicriteria group decision making where the opinions about the criteria values are expressed as HFS. We suppose that in this group decision making problem, $E=\left\{e_{1}, e_{2}, \ldots, e_{K}\right\}, A=\left\{A_{1}, A_{2}, \ldots, A_{m}\right\}$ and $C=\left\{C_{1}, C_{2}, \ldots, C_{n}\right\}$ are the set of the decision makers, alternatives and criteria, respectively.

Step 1. Let $\tilde{X}^{l}=\left[H_{S_{i j}}^{l}\right]_{m \times n}$ be a hesitant fuzzy decision matrix for the multi-criteria group decision making problem where performance of alternative $A_{i}$ with respect to decision maker $e_{l}$ and criterion $C_{j}$ is denoted as $H_{S_{i j}}^{l}$.

Step 2. We produce the single decision matrix $X$ by aggregating the opinions of all the DMs involved in the group decision making problem.

$X=\left[x_{i j}\right]$, where $x_{i j}=\left\{x \mid x \in H_{S_{i j}}^{l}\right.$ and $s_{p_{i j}} \leq x \leq$ $s_{q_{i j}}$ for all $\left.l\right\}$ where

$$
s_{p_{i j}}=\min \left\{\min _{l=1}^{K}\left(\max H_{S_{i j}}^{l}\right), \max _{l=1}^{K}\left(\min H_{S_{i j}}^{l}\right)\right\}
$$

and

$$
s_{q_{i j}}=\max \left\{\min _{l=1}^{K}\left(\max H_{S_{i j}}^{l}\right), \max _{l=1}^{K}\left(\min H_{S_{i j}}^{l}\right)\right\} .
$$




$$
\begin{aligned}
\tilde{A}^{+}=\quad & {\left[x \mid x \in H_{S_{i j}}^{l} \forall i \text { and } \max _{l=1}^{K}\left(\max _{i}\left(\min H_{S_{i j}}^{l}\right)\right) \leq x \leq \max _{l=1}^{K}\left(\max _{i}\left(\max H_{S_{i j}}^{l}\right)\right) \mid j \in \Omega_{b},\right.} \\
& \left.x \mid x \in H_{S_{i j}}^{l} \forall i \text { and } \min _{l=1}\left(\min _{i}\left(\min H_{S_{i j}}^{l}\right)\right) \leq x \leq \min _{l=1}^{K}\left(\min _{i}\left(\max _{S_{i j}}^{l}\right)\right) \mid j \in \Omega_{c}\right] \\
& \mathrm{i}=1,2, \ldots, \mathrm{m}, \text { and } \mathrm{j}=1,2, \ldots, \mathrm{n} . \\
\tilde{A}^{+}=\quad & \left(\tilde{V}_{1}^{+} \tilde{V}_{2}^{+} \ldots \tilde{V}_{n}^{+}\right) \\
\tilde{A}^{-}=\quad & {\left[x \mid x \in H_{S_{i j}}^{l} \forall i \text { and } \max _{l=1}^{K}\left(\max _{i}\left(\min H_{S_{i j}}^{l}\right)\right) \leq x \leq \max _{l=1}^{K}\left(\max _{i}\left(\max H_{S_{i j}}^{l}\right)\right) \mid j \in \Omega_{c},\right.} \\
& \left.x \mid x \in H_{S_{i j}}^{l} \forall i \text { änd } \min _{l=1}^{K}\left(\min _{i}\left(\min H_{S_{i j}}^{l}\right)\right) \leq x \leq \min _{l=1}\left(\min _{i}\left(\max H_{S_{i j}}^{l}\right)\right) \mid j \in \Omega_{b}\right] \\
& \mathrm{i}=1,2, \ldots, \mathrm{m}, \text { and } \mathrm{j}=1,2, \ldots, \mathrm{n} . \\
\tilde{A}^{-}=\quad & \left(\tilde{V}_{1}^{-} \tilde{V}_{2}^{-} \ldots \tilde{V}_{n}^{-}\right)
\end{aligned}
$$

Aggregated performance of alternative $A_{i}$ for criterion $C_{j}$ is denoted as $x_{i j}$, in the final aggregated matrix $X$.

Step 3. Let $\Omega_{b}$ be the collection of all the benefit criteria and $\Omega_{c}$ be the collection of all the cost criteria. The HFS positive-ideal solution (HFSPIS), denoted as $\tilde{A}^{+}=\left(\begin{array}{llll}\tilde{V}_{1}^{+} & \tilde{V}_{2}^{+} & \ldots & \tilde{V}_{n}^{+}\end{array}\right)$, and the HFS negative-ideal solution (HFS-NIS), denoted as $\tilde{A}^{-}=\left(\begin{array}{llll}\tilde{V}_{1}^{-} & \tilde{V}_{2}^{-} & \ldots & \tilde{V}_{n}^{-}\end{array}\right)$, are defined as follows Eq. 1 and 2:

Step 4. The construction of positive ideal separation matrix $\left(D^{+}\right)$and negative ideal separation matrix $\left(D^{-}\right)$are defined as follows Eq. 3 and 4:

Step 5. Calculate the relative closeness $(R C)$ of each alternative to the ideal solution as follows:

$$
R C\left(A_{i}\right)=\frac{D_{i}^{-}}{D_{i}^{+}+D_{i}^{-}}, i=1,2, \ldots, m,
$$

where $D_{i}^{-}={ }_{j=1}^{n} d\left(x_{i j}, \tilde{V}_{j}^{-}\right)$

and $D_{i}^{+}={ }_{j=1}^{n} d\left(x_{i j}, \tilde{V}_{j}^{+}\right)$.

Step 6. Rank all the alternatives $A_{i}(i=$ $1,2, \ldots, m)$ according to the closeness coefficient $R C\left(A_{i}\right)$, the greater the value $R C\left(A_{i}\right)$, the better the alternative $A_{i}$.

\section{Example}

In this Section, we give an example to illustrate the usefulness of the method proposed in Section 3 to get the best alternative. There is an investment company, which wants to invest money in the best option (adapted from [10]). There are five possible alternatives in which to invest the money: $A_{1}$ is a car industry, $A_{2}$ is a food company, $A_{3}$ is a computer company, $A_{4}$ is an arms company, $A_{5}$ is a TV company. The investment company must take a decision according to the following four criteria: $C_{1}$ is the risk analysis; $C_{2}$ is the growth analysis; $C_{3}$ is the social-political impact analysis, $C_{4}$ is the environmental impact analysis. The decision is to be taken by company board of directors i.e. decision makers $e_{K}(K=1,2, \ldots, 10)$.

Step 1. The five possible alternatives $A_{i}(i=1$, $2,3,4,5)$ are to be evaluated using the HFS by ten decision makers $e_{K}(K=1,2, \ldots, 10)$, as listed in Table 1-3.

Step 2. The decision matrix constructed by utilize Table 1-3 is listed in Table 4;

Step 3. For cost criteria $C_{1}, C_{4}$ and benefit criteria $C_{2}, C_{3}$ HFS-PIS $A^{+}$and HFS-NIS $A^{-}$is as follows Eq. 5:

Step 4. Positive ideal matrix $\left(D^{+}\right)$Eq. 6. Negative ideal matrix $\left(D^{-}\right)$Eq. 7: 


$$
\begin{aligned}
D^{+}= & {\left[\begin{array}{ccccccc}
d\left(x_{11}, \tilde{V}_{1}^{+}\right) & + & d\left(x_{12}, \tilde{V}_{2}^{+}\right) & + & \cdots & + & d\left(x_{1 n}, \tilde{V}_{n}^{+}\right) \\
d\left(x_{21}, \tilde{V}_{1}^{+}\right) & + & d\left(x_{22}, \tilde{V}_{2}^{+}\right) & + & \cdots & + & d\left(x_{2 n}, \tilde{V}_{n}^{+}\right) \\
\vdots & & \vdots & & \vdots & & \vdots \\
d\left(x_{m 1}, \tilde{V}_{1}^{+}\right) & + & d\left(x_{m 2}, \tilde{V}_{2}^{+}\right) & + & \cdots & + & d\left(x_{m n}, \tilde{V}_{n}^{+}\right)
\end{array}\right] } \\
D^{-} & =\left[\begin{array}{ccccccc}
d\left(x_{11}, \tilde{V}_{1}^{-}\right) & + & d\left(x_{12}, \tilde{V}_{2}^{-}\right) & + & \cdots & + & d\left(x_{1 n}, \tilde{V}_{n}^{-}\right) \\
d\left(x_{21}, \tilde{V}_{1}^{-}\right) & + & d\left(x_{22}, \tilde{V}_{2}^{-}\right) & + & \cdots & + & d\left(x_{2 n}, \tilde{V}_{n}^{-}\right) \\
\vdots & & \vdots & & \vdots & & \vdots \\
d\left(x_{m 1}, \tilde{V}_{1}^{-}\right) & + & d\left(x_{m 2}, \tilde{V}_{2}^{-}\right) & + & \cdots & + & d\left(x_{m n}, \tilde{V}_{n}^{-}\right)
\end{array}\right]
\end{aligned}
$$

Table 1. Decision matrix $\left(\tilde{X}^{1}\right)$ with respect to $e_{1}, e_{2}, e_{3}$ and $e_{4}$.

\begin{tabular}{l||l|l|l|l} 
& $C_{1}$ & $C_{2}$ & $C_{3}$ & $C_{4}$ \\
\hline \hline$A_{1}$ & $\{0.5,0.6,0.8\}$ & $\{0.6,0.8\}$ & $\{0.1,0.3\}$ & $\{0.1,0.3\}$ \\
\hline$A_{2}$ & $\{0.1,0.3\}$ & $\{0.5,0.7,0.8\}$ & $\{0.5,0.6\}$ & $\{0.5,0.6\}$ \\
\hline$A_{3}$ & $\{0.5,0.7\}$ & $\{0.5,0.6\}$ & $\{0.7,0.9\}$ & $\{0.1,0.2\}$ \\
\hline$A_{4}$ & $\{0.7,0.9\}$ & $\{0.1,0.2\}$ & $\{0.1,0.3\}$ & $\{0.5,0.6,0.7\}$ \\
\hline$A_{5}$ & $\{1\}$ & $\{0.1,0.3\}$ & $\{0,0.2\}$ & $\{0.4,0.7\}$
\end{tabular}

Table 2. Decision matrix $\left(\tilde{X}^{2}\right)$ with respect to $e_{5}, e_{6}$ and $e_{7}$.

\begin{tabular}{l||l|l|l|l} 
& $C_{1}$ & $C_{2}$ & $C_{3}$ & $C_{4}$ \\
\hline \hline$A_{1}$ & $\{0.1,0.2\}$ & $\{0.4,0.9\}$ & $\{0,0.2\}$ & $\{0.4,0.6\}$ \\
\hline$A_{2}$ & $\{0,0.2\}$ & $\{0.1,0.3\}$ & $\{0.4,0.5\}$ & $\{0.6,1\}$ \\
\hline$A_{3}$ & $\{0.4,0.6\}$ & $\{0.1,0.2\}$ & $\{0.4,0.6\}$ & $\{0,0.2\}$ \\
\hline$A_{4}$ & $\{0.6,1\}$ & $\{0.4,0.7\}$ & $\{0,0.1\}$ & $\{0.5,0.7\}$ \\
\hline$A_{5}$ & $\{0.5,0.7\}$ & $\{0.4,0.6\}$ & $\{0,0.1\}$ & $\{0.6,1\}$
\end{tabular}

Table 3. Decision matrix $\left(\tilde{X}^{3}\right)$ with respect to $e_{8}, e_{9}$ and $e_{10}$.

\begin{tabular}{l||l|l|l|l} 
& $C_{1}$ & $C_{2}$ & $C_{3}$ & $C_{4}$ \\
\hline \hline$A_{1}$ & $\{0.4,0.6\}$ & $\{0.6,1\}$ & $\{0.3,0.5\}$ & $\{0,0.3\}$ \\
\hline$A_{2}$ & $\{0.3,0.6\}$ & $\{0.1,0.3\}$ & $\{0.5,0.9\}$ & $\{0.3,0.5\}$ \\
\hline$A_{3}$ & $\{0.1,0.3\}$ & $\{0.6,0.9\}$ & $\{0.3,0.7\}$ & $\{0,0.1\}$ \\
\hline$A_{4}$ & $\{0.6,0.9\}$ & $\{0.5,0.7\}$ & $\{0,0.2,0.4\}$ & $\{0.5,0.6,0.8\}$ \\
\hline$A_{5}$ & $\{0.5,0.6\}$ & $\{0.1,0.3\}$ & $\{0.2,0.4\}$ & $\{1\}$
\end{tabular}

Table 4. Decision matrix $(X)$.

\begin{tabular}{rl||l|l|l|l} 
& $C_{1}$ & $C_{2}$ & $C_{3}$ & $C_{4}$ \\
\hline \hline$A_{1}$ & $\{0.2,0.4,0.5\}$ & $\{0.6,0.8\}$ & $\{0.2,0.3\}$ & $\{0.3,0.4\}$ \\
\hline$A_{2}$ & $\{0.2,0.3\}$ & $\{0.3,0.5\}$ & $\{0.5\}$ & $\{0.5,0.6\}$ \\
\hline$A_{3}$ & $\{0.3,0.4,0.5\}$ & $\{0.2,0.5,0.6\}$ & $\{0.6,0.7\}$ & $\{0.1\}$ \\
\hline$A_{4}$ & $\{0.7,0.9\}$ & $\{0.2,0.4,0.5\}$ & $\{0.1\}$ & $\{0.5,0.6,0.7\}$ \\
\hline$A_{5}$ & $\{0.6,0.7,1\}$ & $\{0.3,0.4\}$ & $\{0.1,0.2\}$ & $\{0.7,1\}$ \\
$\mathrm{A}^{+}=\left[\begin{array}{lllll}\{0,0.1,0.2\} & \{0.6,0.7,0.8,0.9,1\} & \{0.7,0.8,0.9\} & \{0,0.1\}\end{array}\right]$ \\
$\mathrm{A}^{-}=\left[\begin{array}{lllll}00.7,0.8,0.9\} & \{0.1,0.2\} & \{0,0.1\} & \{1\}\end{array}\right]$
\end{tabular}




$$
\begin{aligned}
& D^{+}=\left[\begin{array}{ccccccc}
0.3 & + & 0.2 & + & 0.6 & + & 0.3 \\
0.2 & + & 0.5 & + & 0.4 & + & 0.5 \\
0.3 & + & 0.4 & + & 0.2 & + & 0.1 \\
0.7 & + & 0.5 & + & 0.8 & + & 0.6 \\
0.8 & + & 0.6 & + & 0.7 & + & 0.9
\end{array}\right]=\left[\begin{array}{l}
1.4 \\
1.6 \\
1.0 \\
2.6 \\
3.0
\end{array}\right] \\
& D^{-}=\left[\begin{array}{ccccccc}
0.5 & + & 0.6 & + & 0.2 & + & 0.7 \\
0.6 & + & 0.3 & + & 0.5 & + & 0.5 \\
0.4 & + & 0.4 & + & 0.6 & + & 0.9 \\
0.1 & + & 0.3 & + & 0.1 & + & 0.5 \\
0.1 & + & 0.2 & + & 0.1 & + & 0.3
\end{array}\right]=\left[\begin{array}{l}
2.0 \\
1.9 \\
2.3 \\
1.0 \\
0.7
\end{array}\right]
\end{aligned}
$$

Step 5. Relative closeness (RC) of each alternative to the ideal solutions:

$$
\begin{aligned}
& R C\left(A_{1}\right)=2 /(1.4+2)=0.5882 ; \\
& R C\left(A_{2}\right)=1.9 /(1.9+1.6)=0.5429 ; \\
& R C\left(A_{3}\right)=2.3 /(2.3+1)=0.6970 ; \\
& R C\left(A_{4}\right)=1.0 /(1.0+2.6)=0.2778 ; \\
& R C\left(A_{5}\right)=0.7 /(0.7+3)=0.1892 .
\end{aligned}
$$

Step 6. Rank all the alternatives $A_{i}(i=$ $1,2, \ldots, 5)$ according to the closeness coefficient $R C\left(A_{i}\right)$ :

$A_{3} \succ A_{1} \succ A_{2} \succ A_{4} \succ A_{5}$.

So the most suitable alternative is $A_{3}$.

\section{Acknowledgment}

The authors would like to thank the editors and the anonymous reviewers, whose insightful comments and constructive suggestions helped us to significantly improve the quality of this paper.

\section{References}

[1] B. Ashtiani, F. Haghighirad, A. Makui and G. Montazer, Extension of fuzzy TOPSIS method based on interval-valued fuzzy sets, Applied Soft Computing, 9(2), 2009, 457-461

[2] I. Beg and T. Rashid, Multi-criteria trapezoidal valued intuitionistic fuzzy decision making with Choquet integral based TOPSIS, OPSEARCH, 51(1), 2014, 98-129

[3] I. Beg and T. Rashid, TOPSIS for hesitant fuzzy linguistic term sets, International Journal of Intelligent Systems, 28, 2013, 1162-1171
[4] R. E. Bellman and L. A. Zadeh, Decision making in a fuzzy environment, Management Science, 17(4), 1970, 141-164

[5] F. E. Boran, S. Gen, M. Kurt and D. Akay, A multicriteria intuitionistic fuzzy group decision making for supplier selection with TOPSIS method, Expert Systems with Applications, 36, 2009, 11363-11368

[6] C. T. Chen, Extensions of the TOPSIS for group decision-making under fuzzy environment, Fuzzy Sets and Systems, 114, 2000) 1-9

[7] S. J. Chen and C. L. Hwang, Fuzzy multiple attribute decision making, Berlin: Springer, 1992)

[8] T.-C. Chu and Y.-C. Lin, An interval arithmetic based fuzzy TOPSIS model, Expert Systems with Applications, 36, 2009, 10870-10876

[9] D. Dubois, The role of fuzzy sets in decision sciences: Old techniques and new directions, Fuzzy Sets and Systems, 184, 2011, 3-28

[10] F. Herrera, E. Herrera-Viedma and L. Martinez, A fusion approach for managing multi-granularity linguistic term sets in decision making, Fuzzy Sets and Systems, 114, 2000, 43-58

[11] C. L. Hwang and K. Yoon, Multiple attributes decision making methods and applications, Berlin, Heidelberg: Springer, 1981)

[12] G. R. Jahanshahloo, H. F. Lotfi and M. Izadikhah, Extension of the TOPSIS method for decisionmaking problems with fuzzy data, Applied Mathematics and Computation, 181(2), 2006, 1544-1551

[13] J. Jiang, Y.-W. Chen, Y.-W. Chen, K.-W. Yang, TOPSIS with fuzzy belief structure for group belief multiple criteria decision making, Expert Systems with Applications, 38, 2011, 9400-9406

[14] T. Kaya and C. Kahraman, Multicriteria decision making in energy planning using a modified fuzzy TOPSIS methodology, Expert Systems with Applications, 38(6), 2011, 6577-6585 
[15] G. Kim, C. Park and K. Yoon, Identifying investment opportunities for advanced manufacturing systems with comparative-integrated, International Journal of Production Economics, 50, 1997, 23-33

[16] M. S. Kuo, G. H. Tzeng and W. C. Huang, Group decision-making based on concepts of ideal and anti-ideal points in a fuzzy environment, Mathematical and Computer Modelling, 45, 2007, 324-339

[17] I. Mahdavi, N. Mahdavi-Amiri, A. Heidarzade and R. Nourifar, Designing a model of fuzzy TOPSIS in multiple criteria decision making, Applied Mathematics and Computation, 206, 2008, 607-617

[18] D. S. Negi, Fuzzy analysis and optimization, $\mathrm{PhD}$ thesis. Department of Industrial Engineering, Kansas State University, 1989)

[19] J. Peng, J. Wang, J. Wang, L. Yang and X. Chen, An extension of ELECTRE to multi-criteria decision-making problems with multi-hesitant fuzzy sets. Information Sciences, 307, 2015, 113-126

[20] T. Rashid, I. Beg and S. M. Husnine, Robot selection by using generalized interval-valued fuzzy numbers with TOPSIS, Applied Soft Computing. Applied Soft Computing, 21, 2014, 462-468

[21] R. M. Rodriguez, L. Martinez and F. Herrera, Hesitant fuzzy linguistic term sets for decision making, IEEE Transaction on fuzzy Systems 20(1), 2012, $109-118$

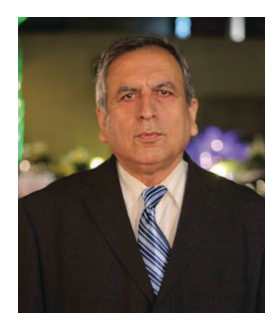

Ismat Beg received his Ph.D. degree in mathematics from University of Bucharest in 1982. He is Professor at Lahore School of Economics. He has vast experience of teaching and research. His field of interest and specialization is versatile in nature. It covers many areas of mathematics, economics, engineering, decision theory, computer science and social sciences. He has published more than 250 papers. He is a Fellow of Pakistan Academy of Sciences, and Institute of Mathematics and its Applications (IMA). For more detail see https://www.researchgate.net/profile/Ismat_Beg
[22] H. Shih, H. Shyur and E. Lee, An extension of TOPSIS for group decision making, Mathematical and Computer Modelling, 45, 2007, 801-813

[23] V. Torra, Hesitant fuzzy sets, International Journal of Intelligent Systems, 25(6), 2010, 529-539

[24] T. C. Wang and T. H. Chang, Application of TOPSIS in evaluating initial training aircraft under a fuzzy environment, Expert Systems with Applications, 33, 2007, 870-880

[25] J. H. Wang and J. Y. Hao, A new version of 2-tuple fuzzy linguistic representation model for computing with words, IEEE Transactions on Fuzzy Systems, 14(3), 2006, 435-445

[26] Y. J. Wang and H. S. Lee, Generalizing TOPSIS for fuzzy multiple-criteria group decision-making, Computers and Mathematics with Applications, 53, 2007, 1762-1772

[27] G. Wei, Hesitant fuzzy prioritized operators and their application to multiple attribute decision making, Knowledge-Based Systems 31, 2012, 176-182

[28] M. Xia and Z. Xu, Hesitant fuzzy information aggregation in decision making, International Journal of Approximate Reasoning, 52, 2011, 395-407

[29] Z. Xu and M. Xia, On distance and correlation measures of hesitant fuzzy information, International Journal of Intelligent Systems, 26, 2011, 410425

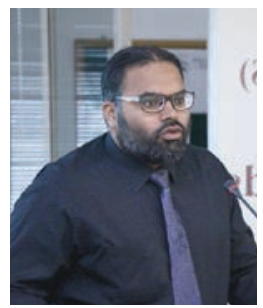

Dr. Tabasam Rashid obtained his B.S. mathematics in 2008 from University of the Punjab. He completed his M.S. degree in 2010 and obtained his Ph.D. in 2015 from National University of Computer and Emerging Sciences. He is currently working with University of Management and Technology as an Assistant Professor, where he won the best research award for the year 2015. Currently he is working in decision making, Choquet integral, judgment aggregation, information fusion and preference modeling using fuzzy set theory and soft set theory. He is a reviewer of many international journals and American Mathematical Society. 